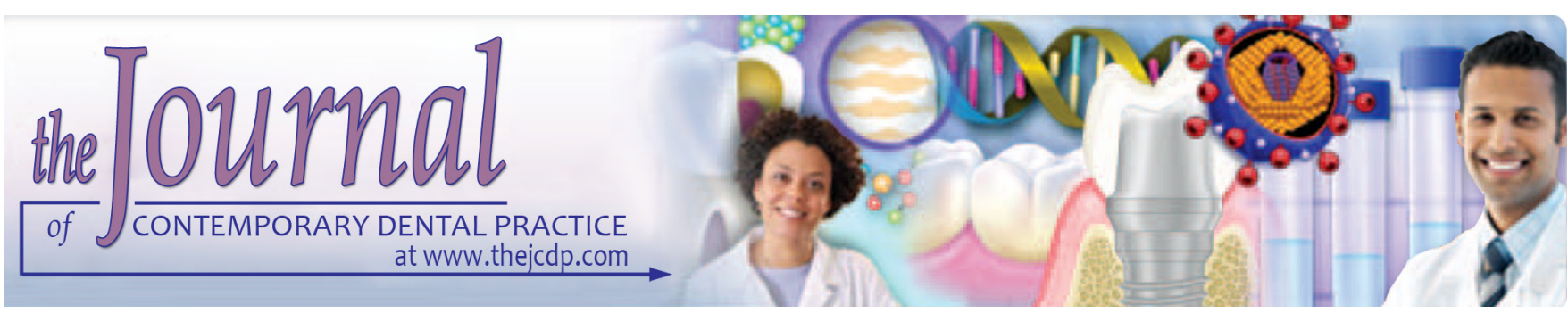

\title{
Sealing Capacity of Bulk-fill Resin in Endodontically Treated Teeth
}

\author{
${ }^{1}$ Mônica S de Albuquerque, ${ }^{2}$ Armiliana S Nascimento, ${ }^{3}$ Kêsia XFR de Sena, ${ }^{4}$ Carlos VJ Oliveira, ${ }^{5}$ Leonardo JR Oliveira, \\ ${ }^{6}$ Marianne V Carvalho, ${ }^{7}$ Maria HA Cavalcanti, ${ }^{8}$ Rodivan Braz
}

\section{ABSTRACT}

Aim: The objective of the study is to evaluate the cervicalapical sealing of bulk-fill flow resins associated with a universal adhesive system, in endodontically treated teeth, considering two methods of evaluation.

Materials and methods: The samples used in the bacterial leakage analysis were autoclaved, filled inside a laminar flow chamber, and divided into four experimental groups $(n=8)$ according to the restorative material: Filtek Bulk-fill flow; Surefil SDR flow; TetricEvoflow and the positive control. The samples were inoculated with the Enterococcus faecalis (E. faecalis), every 7 days and the microleakage was evaluated on a daily basis for 60 days. Microleakage tested with dye $(n=5)$ was considered in 2-time intervals of evaluation (24 hours and 72 hours), and the results were obtained in scores from $0-5$. Data were submitted to the statistical tests, at a level of significance of 0.05 .

Results: About $12.5 \%$ of the FBF specimens showed bacterial microleakage as from the thirteenth day, and SDR, from the 20th day. TEF presented the highest percentage of microleakage at 40 days, concluding the 60 days with $37.5 \%$ of viable specimens. The Log-rank test revealed that the survival curve of TEF was statistically significant in comparison with those of the other groups. In the test with dye TEF and SDR presented the highest and lowest rate of microleakage, respectively, with statistically significant differences in the time interval of $72 \mathrm{~h}$.

Conclusion: The resins FBF, SDR, and TEF were incapable of promoting the hermetic sealing of fillings in the root canal system.

\footnotetext{
1,2, 5-8 Department of Dentistry, University of Pernambuco-UPE Av. General Newton Cavalcanti, Tabatinga Camaragibe PE, Brazil

${ }^{3,4}$ Department of Antibiotics, Federal University of Pernambuco. Street: Universitária, Recife-PE, Brazil
}

Corresponding Author: Mônica $S$ de Albuquerque, Department of Dentistry, University of Pernambuco-UPE. Av. General Newton Cavalcanti, Tabatinga CamaragibePE, Brazil, Phone: +55 (81) 995432705, e-mail: santos. albuquerque@hotmail.com
Clinical significance: No bulk-fill flux studied was able to completely eliminate microleakage, despite the best performance with respect to the microleakage time presented by Filtek Bulk fill, followed by Surefil SDR flow.

Keywords: Bacterial microleakage, Bulk-fill, Composites, Dye microleakage, Enterococcus faecalis.

How to cite this article: Albuquerque MSD, Nascimento ASde, de Sena KXFR, Oliveira CVJ, Oliveira LJR, Carvalho MV, Cavalcanti MHA, Braz R. Sealing Capacity of Bulk-fill Resin in Endodontically Treated Teeth. J Contemp Dent Pract 2019;20(3):311-317.

Source of support: Nil

Conflict of interest: None

\section{INTRODUCTION}

Bacterial microleakage between the tooth and filling material continues to be one of the main causes of endodontic treatment failure. Therefore, hermetical cervical sealing is fundamental for impeding or minimizing the penetration of microorganisms. ${ }^{1,2}$ However, in spite of various methods and materials having been suggested to promote this sealing, whether or not the materials used at present are effective, is still a questionable issue. ${ }^{3,4}$ Factors such as the lack of bonding to dental tissue; polymerization shrinkage of composites, and the difference in the linear thermal expansion coefficient between the tooth and restorative material have led to inadequate cervical sealing. ${ }^{5-7}$

Seeking to improve the properties of restorative materials, new composite denominated the bulk-fill type have been launched. The characteristic of these materials is that they can be inserted in a single increment of 4-6 $\mathrm{mm} .{ }^{8}$ According to the manufacturers' recommendations, their adequate polymerization associated with lower contraction stress can be achieved. According to the literature, the lower contraction stress results from the use of specific polymerization modulators and because 
they have a low modulus of elasticity. The greater polymerization depth is derived from the use of more potent photoinitiators and their higher translucency that allows more light to penetrate. ${ }^{9}$ In addition, the presentation in fluid form allows better adaptation to and filling of the undercut root canal walls.

These composites may be associated with conventional and universal adhesive systems. According to Yoshida et al., ${ }^{10}$ when using an adhesive system that has MDP monomer (10-Methacryloyloxydecyl dihydrogen phosphate) in its composition, with potential for chemical bonding, gap formation may be minimized by increasing the bond strength between the (tooth/ material) substrates.

The aim of this study was to evaluate the cervical sealing capacity of the bulk-fill flow resins in endodontically treated teeth, considering two methods of evaluation. Three hypotheses were tested:

- $H_{0}$ : The association of bulk-fill flow resins with universal adhesive would not impede bacterial microleakage

- $H_{1}$ : the time interval of evaluation would not influence the microleakage results

- $\mathrm{H}_{2}$ : there would be no difference between the methods of evaluation.

\section{MATERIALS AND METHODS}

\section{Selection, Standardization of Samples, and Division of the Groups}

Fifty-nine maxillary bovine incisors with closed apices and square roots, and of similar shapes and sizes were included in this study. The roots were a section at 16 $\mathrm{mm}$ from the apical foramen, and the real working length (RWL) was determined $1 \mathrm{~mm}$ short of the apex $(15 \mathrm{~mm})$. Instrumentation was performed with Gates Glidden (Maillefer-Dentsply-Brazil) burs from number 6 to 3 in the cervical and middle thirds, and the apical stop was prepared at the RWL up to $80 \mathrm{k}$-file (Maillefer, Switzerland). Irrigation was performed with $5 \mathrm{~mL}(2.5 \%)$ sodium hypochlorite at every change of file. On conclusion of instrumentation, the canal was inundated with EDTA (17\%), mechanically agitated for 3 minutes with file $20 \mathrm{k}$, and afterward irrigated with $\mathrm{NaOCl}(2.5 \%)$, aspiration and dry with absorbent paper points (Maillefer-Dentsply). On conclusion of chemicalmechanical preparation, the 120 root remainders were randomly divided into two experimental groups according to the evaluation technique: group 1evaluated by means of bacterial penetration, and group 2 -evaluated with dye, followed by filling the canals. The samples of group 1 were sealed with 02 coats of cosmetic varnish (Colorama, Maybelline, Nova York,
USA) leaving the $2 \mathrm{~mm}$ short of the apex and the initial $1 \mathrm{~mm}$ of the cervical third free of varnish, and then autoclaved $\left(121^{\circ} \mathrm{C} / 20 \mathrm{~min}\right)$, filled in a laminar flow chamber. After filling, $2 \mathrm{~mm}$ of the gutta-percha was removed from the canal entrances, for later restoration, according to each experimental material $(n=8)$. Filtek bulk-fill flow (3M/ESPE St. Paul, MN, USA), Surefil SDR flow (Dentsply Petrópolis, Brazil) and TetricEvoflow (Ivoclar Vivadent AG Schaan, Germany) in accordance with the respective manufacturer's recommendations (Table 1). The positive control $(n=5)$ considered only the root remainders without endodontic treatment, and the negative $(n=5)$, only the sterile BHI culture medium. As restorative protocol, the adhesive system All Bond Universal (BISCO-Germany) was used in accordance with the manufacturer's instructions (Table 1), with later insertion and light polymerization of the resin, with the use of a Radii cal (SDI-Australia) Light Polymerizing appliance, at $1200 \mathrm{~mW} / \mathrm{cm}^{2}$.

\section{Fabrication of Device for Bacterial Infiltration/ Leakage Test}

For the bacterial leakage test, a device was fabricated, based on the model proposed by Torabinejad et al..$^{11}$ with modifications (Fig. 1). Initially, the extremities of sterile Eppendorf tubes were cuts with a no. 15 scalpel blade (Lamedid Solidor) so that when the tooth was inserted, $2 \mathrm{~mm}$ of the apical third of the filled roots would remain outside of the tube. The connection between the root and Eppendorf tube was sealed with acrylic resin (Vipiflash, Madespa S/A, Rio de Janeiro, Brazil) to prevent bacterial leakage. Crepe tape (3M) was placed around the edge of the Eppendorf tubes, to seal the space between the tube and flask, for the purpose of preventing external contamination. After sealing the extremities, the Eppendorf/Specimen sets were placed in sterile glass jars, containing $4 \mathrm{~mL}$ BHI medium (liquid brain heart infusionOxoid Ltda., Basingstoke, Hampshire, England) so that $2 \mathrm{~mm}$ of the apical portion would remain immersed in the culture medium.

\section{Obtainment, Inoculation, and Evaluation of Infiltration/Leakage of Enterococcus faecalis}

The E. faecalis strain was obtained from the Microorganism Culture Collection of the Department of Antibiotics of the Federal University of Pernambuco (UFPEDA 138). The E. faecalis was cultivated on BHI agar for 24 hours. A sample of the bacterial growth was suspended in $2 \mathrm{Ll}$ sterile saline solution (tube 1), and afterward, the density of the suspension was adjusted according to Tube 05 on the scales of the McFarland turbidity meter $\left(1 \times 10^{8} \mathrm{CFU} / \mathrm{mL}\right)$. After this a dilution (1:10) was made by transferring 200 


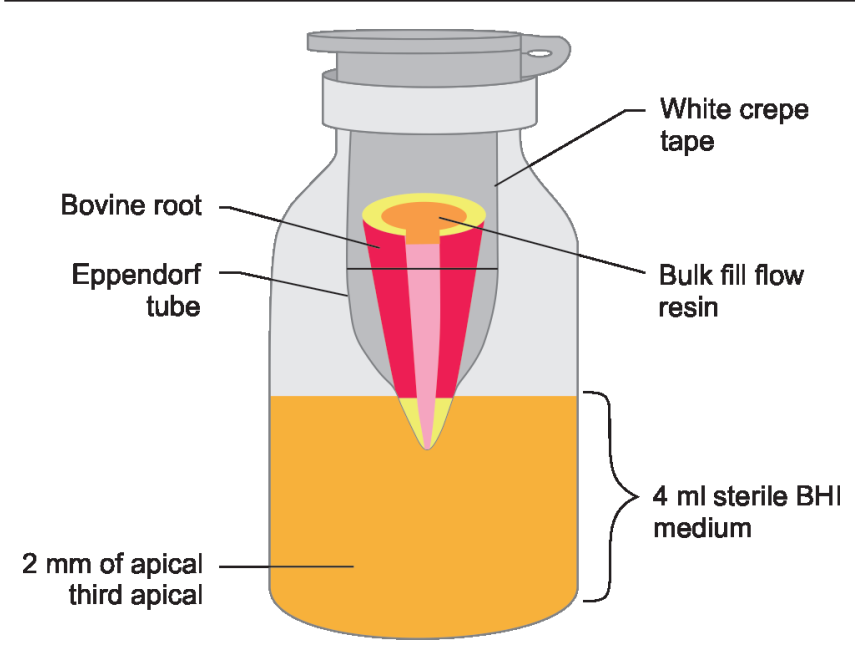

Fig. 1: Illustration of the device used to evaluate bacterial infiltration/leakage

$\mu \mathrm{L}$ of the suspension of Tubes 1 and 2 containing $1.8 \mathrm{~mL}$ sterile saline solution, resulting in a bacterial suspension of $1 \times 10^{7} \mathrm{CFU} / \mathrm{mL}$. Each sample of the experimental materials was inoculated with $10 \mu \mathrm{L}$ of the bacterial suspension every 7 days, for 60 days $\left(35^{\circ} \mathrm{C}\right)$. Daily evaluations (24 hours) were made to verify the volume and presence, and/or absence of bacterial growth in the culture medium. When turbidity of the culture medium occurred, the sample was removed, and the microbial agent was identified with the purpose of proving the presence of E. faecalis. The proofs of identification used for confirming the bacterial agent were gram staining, Bile-Esculin test and growth in saline BHI $(6.5 \% \mathrm{NaCl})$.

\section{Evaluation of Microleakage with Dye Solution}

Before immersing the specimens in dye, the apical foramina of the roots were sealed with composite resin (Z100, 3M ESPE). Subsequently, the roots were sealed with two coats of nail varnish (Colorama, Maybelline, Nova York, USA) respecting the distance of $1 \mathrm{~mm}$ of the most cervical portion, thermal cycled ( 5000 cycles: $5-55^{\circ} \mathrm{C} / \mathrm{min}$ ), immersed in dye (2\% methylene blue) for 24 hours and 72 hours, washed in running water, dried with absorbent paper, and longitudinally section in the mesiodistal direction, with the use of a double-faced diamond disc (KG Sorensen), fitted to a (low speed) micromotor. Each hemisection was given a code number that was cataloged according to its experimental group. The microleakage at the tooth/restoration interface in the cervical region was quantitatively evaluated, with the aid of a stereoscopic lens (Coleman Equipamentos para Laboratórios Comércio e Importação Ltda., Santo André SP, Brazil), at 40x magnification, by 03 previously calibrated examiners, using the following criteria: 0 -Without leakage at the restoration margins; 1 - Leakage at the restoration margins that did not attain the restoration/ filling limit; 2-Leakage at the restoration margins attaining the restoration/filling limit; 3-Leakage attaining the

Table 1: Materials used in the study (Information provided by manufacturers)

\begin{tabular}{|c|c|c|c|c|c|c|}
\hline & $\begin{array}{l}\text { Material and } \\
\text { manufactured batch no }\end{array}$ & Monomers & Filers & $\begin{array}{l}\text { Phatoinitiators/ } \\
\text { Coiniciators }\end{array}$ & Shade & $\begin{array}{l}\text { Thickness }(\mathrm{mm}) / \text { curing } \\
\text { time and light Intensity }\end{array}$ \\
\hline FBFF & $\begin{array}{l}\text { Filtek Bulk Fill Flow }^{\mathrm{TM}} \\
\text { (3M/ESPE St. Paul, } \\
\text { MN, USA)-N735392 }\end{array}$ & $\begin{array}{l}\text { Bis-GMA } \\
\text { UDMA } \\
\text { Bis-EMA } \\
\text { Procrylat }\end{array}$ & $\begin{array}{l}\text { Triflureto de } \\
\text { itérbio Zirconia/ } \\
\text { sílica - } 64 \text { wt \%, } \\
42.5 \text { vol }\end{array}$ & NA & A2 & $\begin{array}{l}4 \mathrm{~mm} / 20 \mathrm{~s} \geq 1000 \\
\mathrm{~mW} / \mathrm{cm}^{2} \text { ou } 40 \mathrm{~s} \\
550-1000 \mathrm{~mW} / \mathrm{cm}^{2} \\
\text { (halogen or LED) }\end{array}$ \\
\hline SDR & $\begin{array}{l}\text { SureFil@ SDR Flow TM } \\
\text { (DENTSPLY Petropolis, } \\
\text { Brasil)-160613 }\end{array}$ & $\begin{array}{l}\text { Modified } \\
\text { UDMA } \\
\text { EBPADMA } \\
\text { TEGDMA }\end{array}$ & $\begin{array}{l}\text { Barium and } \\
\text { strontium } \\
\text { alumino-fluoro } \\
\text { silicate glasses - } \\
68 \mathrm{wt} \% \text {, } \\
44 \mathrm{vol} \%\end{array}$ & $\begin{array}{l}\text { Camphoroquinone } \\
\text { (CQ) BHT, UV } \\
\text { Stabilizer } \\
\text { Titanium dioxide } \\
\text { Iron oxide pigments } \\
\text { Fluorescing agent }\end{array}$ & $U$ & $\begin{array}{l}4 \mathrm{~mm} / 20 \mathrm{~s} 500-1000 \\
\mathrm{~mW} / \mathrm{cm} 2 \text { (LED and } \\
\text { halogen) ou 10s } \\
\text { (high power lights) }\end{array}$ \\
\hline TEF & $\begin{array}{l}\text { Tetric EvoFlow Bulk Fill@ } \\
\text { (IVOCLAR VIVADENT } \\
\text { Amherst, } \\
\text { NY, USA)-U41169 }\end{array}$ & $\begin{array}{l}\text { Bis-GMA } \\
\text { Bis-EMA } \\
\text { UDMA }\end{array}$ & $\begin{array}{l}\text { Prepolymer } \\
\text { fillers } \\
\text { Barium glass } \\
\text { filler, ytterbium } \\
\text { fluoride and } \\
\text { spherical mixed } \\
\text { oxide fillers - } \\
62.5 \mathrm{wt} \% \text {, } \\
60 \mathrm{vol} \%\end{array}$ & $\begin{array}{l}\text { Camphorquinone/ } \\
\text { amine Highly } \\
\text { reactive, patented } \\
\text { Ivocerin light initiator }\end{array}$ & $U$ & $\begin{array}{l}4 \mathrm{~mm} / 20 \mathrm{~s} \geq 600 \mathrm{~mW} / \\
\mathrm{cm}^{2} \\
10 \mathrm{~s} \geq 1000 \mathrm{~mW} / \mathrm{cm}^{2}\end{array}$ \\
\hline$A B U$ & $\begin{array}{l}\text { All Bond Universal } \\
\text { (BISCO USA)-B-72020K }\end{array}$ & $\begin{array}{l}\text { Bis-GMA, } \\
10-M D P, \\
\text { HEMA, } \\
\text { ethanol, } \\
\text { initiators, } \\
\text { water }\end{array}$ & \multicolumn{4}{|c|}{$\begin{array}{l}\text { Apply first layer, brush for } 20 \text { s. Dry lightly (30s) Apply second layer, brush for } \\
20 \text { s. Dry lightly (30s) Light curing (10s) }\end{array}$} \\
\hline
\end{tabular}

UDMA: urethane dimethacrylate, Bis-GMA: bisphenol A glycidyl methacrylate, Bis-EMA: ethoxylated bisphenol A glycol dimethacrylate, EBPADMA: ethoxylated bisphenol A dimethacrylate, TEGDMA: Tetraethyleneglycol Dimethacrylate, 
cervical third of the filling; 4-Leakage attaining the middle third of the filling; 5-Leakage attaining the apical third of the filling.

\section{Statistical Analysis}

The bacterial microleakage data were submitted to the Fisher's exact test and Kaplan-Meyer survival curves, and the Long-Rank test. The microleakage data obtained with dye in the time intervals of 24 hours and 72 hours were analyzed using the Mann-Whitney and Kruskal-Wallis tests in the comparison between resins for each time interval of evaluation. All the tests were performed with the use of SPSS version 23 and Medcalc version 14.8.1, considering a level of significance of 0.05 .

\section{RESULTS}

Table 2 presents the percentage of bacterial microleakage according to the material and time interval of evaluation. By means of the Fisher's exact test, no statistically significant difference was observed among the materials evaluated. When the time interval of the evaluation was considered, the resin TEF was the type with the most samples showing leakage, especially after 40 days, nevertheless, without statistically significant differences. By means of the Log-rank test, a significant difference was proved between the survival curves $(p=0.007)$ (Graph 1).

Table 3 presents estimates of means and medians and result of the statistical test for comparison between groups. This table shows that the time estimates were higher in groups FBFF (56.12 days) and SDR (54.63 days) when compared with group TEF (35.25 days). The median could only be determined in the TEF group.

The mean and standard deviation values of the microleakage scores with dye, according to the resin and time interval of evaluation are described in Table 4. Group TEF presented the highest microleakage scores in the two-time intervals of evaluation, with significant differences between the other resins in the evaluation at 72 hours. Graph 2 shows the percentage of microleakage between the materials, according to the time intervals of evaluation.

\section{DISCUSSION}

To evaluate the cervical-apical sealing capacity of the bulk fill resins associated with the use of a universal adhesive system in endodontically treated teeth, two methodologies were used. Three hypotheses were raised, and the results let to the rejection of the first null hypothesis that reported on the capacity of the association between resins and the adhesive system for impeding the penetration of

Table 2: Perccentage of bacterial microleakage according to the material and time interval of evaluation

\begin{tabular}{|c|c|c|c|c|c|c|c|}
\hline \multirow{2}{*}{$\begin{array}{l}\text { Dias de } \\
\text { Avaliação }\end{array}$} & \multicolumn{2}{|c|}{$F B F F$} & \multicolumn{2}{|c|}{ SDR } & \multicolumn{2}{|c|}{ TEF } & \multirow[b]{2}{*}{$p$ value } \\
\hline & $N$ & $\%$ & $N$ & $\%$ & $N$ & $\%$ & \\
\hline 1 & 8 & 100,0 & 8 & 100,0 & 8 & 100,0 & $p(1)=1,000$ \\
\hline 10 & 8 & 100,0 & 8 & 100,0 & 7 & 87,5 & $p(1)=1,000$ \\
\hline 20 & 8 & 100,0 & 7 & 87,5 & 6 & 75,0 & $p(1)=0,747$ \\
\hline 30 & 7 & 87,5 & 7 & 87,5 & 4 & 50,0 & $p(1)=0,278$ \\
\hline 40 & 7 & 87,5 & 7 & 87,5 & 3 & 37,5 & $p(1)=0,062$ \\
\hline 60 & 7 & 87,5 & 7 & 87,5 & 3 & 37,5 & $p(1)=0,062$ \\
\hline
\end{tabular}

(1) By means of Fisher's exact test. (N) Number of teeth without infiltration

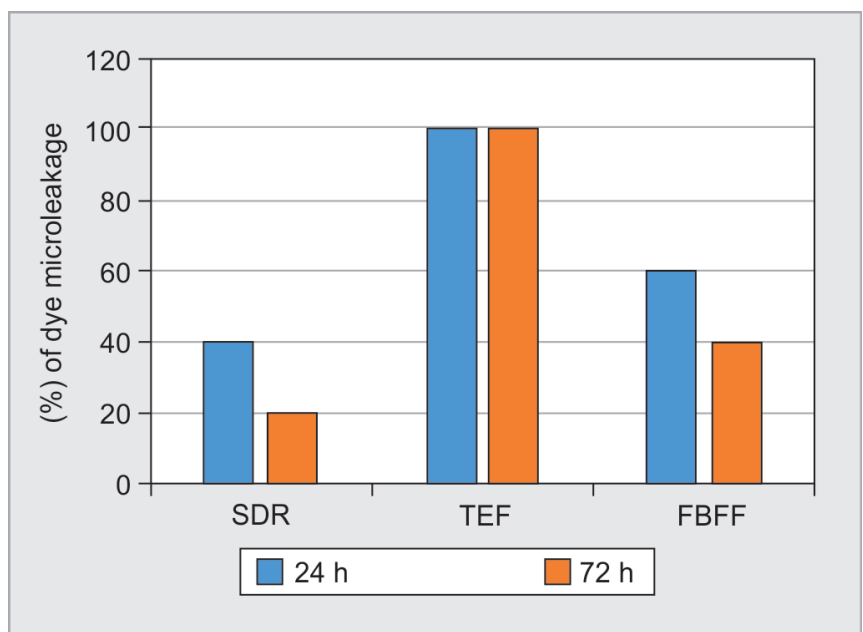

Graph 1: Percentage of micro-leakage on tooth surface with the composite materials

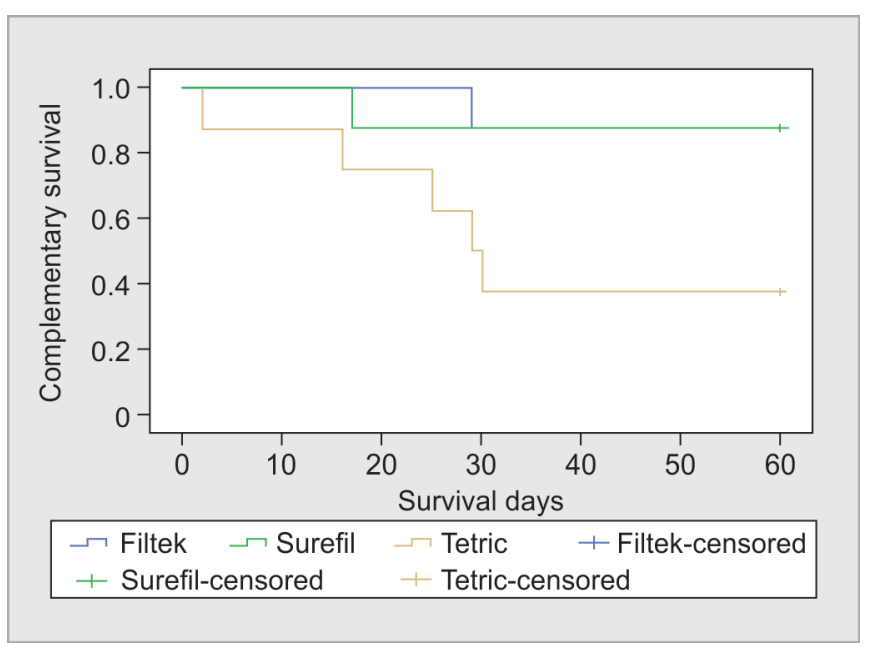

Graph 2: Kaplan-Meier curves of resins relative to bacterial microleakage 
microorganisms. All the resins enabled penetration of the microorganism, with consequent contamination of the culture medium. The resins FBFF and SDR had 12.5\% of their samples with detectable microleakage in 30 and 20 days, respectively and presented a similar percentage of leakage between them after 30 days. Whereas, tetric had $12.5 \%$ of its samples contaminated in 10 days; $25 \%$ in 20 days; $50 \%$ in 30 days, and $62.5 \%$ in 40 days, remaining stable up to the end of the 60 days. The similarity of the results between the FBFF and SDR groups could bejustified by the similarity in their chemical composition (organic), both being methacrylate-based; and in the filler content of each of them, which was $64.5 \%$ (FBFF) and $68 \%$ (SDR). ${ }^{12,13}$ Paradoxically, TEF presented a larger filler content (71\% by weight) and consequently should have had a lower level of polymerization shrinkage due to the reduction in organic content, resulting in a lower rate of leakage. However, some hypotheses could be related to this result. One of these was the possibility of a restriction in the mobility of the reactive species, and scattered diffusion of the light activator may have occurred..$^{14}$ Another explanation would be related to the chemical composition of the new initiator (IVOCERIN) that may have influenced the performance of this resin. On the other hand, considering that all the resins were used in accordance with their manufacturer's recommendations, using the All Bond Universal adhesive system, for analysis of the results presented, the restorative system must be considered as a whole; that is, the "adhesive system + resin composite" set.

With regard to the time interval of evaluation, the

Table 3: Estimates of the mean and median of time (days) without infiltration/leakage according to group

\begin{tabular}{lllll}
\hline \multirow{2}{*}{ Group } & \multicolumn{2}{l}{ Estimates of the mean } & \multicolumn{2}{l}{ Estimates of the median } \\
\cline { 2 - 5 } & Value & (IC 95\%) & Value & (IC 95\%) \\
\hline FBFF & 56.12 & $(49.02$ to & - & - \\
& & $63.23)$ & & - \\
SDR & 54.63 & $(44.77$ to & - & \\
& & $64.48)$ & \\
TEF & 35.25 & $(20.79$ to & 29.00 & $(22.07$ to \\
& \multicolumn{5}{c}{$49.71)$} \\
p value & \multicolumn{3}{c}{$p(1)=0.031^{*}$} & $35.93)$
\end{tabular}

(1) By means of the Log-Rank test. (-) could not be determined because the infiltration/leakage occurred in fewer than half of the specimens in the group authors noted that the longer the period of exposure was, the greater were the chances of contamination, which led to the rejection of the second hypothesis. The results obtained in this study corroborated the findings of Torabinejad et al., ${ }^{11}$ in which over $50 \%$ of the root canals were contaminated by Staphylococcus epidermidis after 19 days; and $50 \%$ by Proteus vulgaris in up to 42 days. Whereas, Khayat et al. ${ }^{15}$ reported that the contamination of DTE exposed to saliva occurred in fewer than 30 days, a result that was partly similar to that obtained in the TEF group, which showed leakage in $50 \%$ of its samples in this time interval. The short period of contamination of this same group agreed with the data of the study of Chailertvanitkul et al. ${ }^{16}$ in which the time necessary for leakage with E. faecalis to occur ranged from 7 to 86 days. Bacterial tracers have been wisely used to provide data that are biologically and clinically more significant and relevant when compared with other methods. ${ }^{17}$

Dyes and radioactive isotopes are also substances that may be used to evaluate microleakage, and however, due to their reduced sizes, they may not reproduce the true result presented when microorganisms and their by-products are used. ${ }^{15}$ In this study, an analysis with dyes ( $2 \%$ methylene blue) was also performed, and the results were shown to be similar to those obtained in the analysis with microorganisms. The samples of all the resins showed microleakage, however TEF present $100 \%$ microleakage with dye after thermal cycling in the two-time intervals of evaluation. The results showed that in the two methods of evaluation used, the resins were incapable of promoting hermetical cervical-apical sealing, and that resin TEF presented the highest rates of microleakage in both methods. This led to the acceptance of the third hypothesis that related there would be no difference between the methods of evaluating microleakage. However, according to Barthel et al., ${ }^{18}$ the results obtained in the analysis with dye cannot be extrapolated to comparisons with bacterial microleakage, or with the events that occur in in vivo procedures.

The method of evaluation with dyes is influenced by the capacity for dye penetration and by the intraand inter-examiner reliability, which must not be

Table 4: Mean and standard deviation of microleakage according to the material and time interval of evaluation

\begin{tabular}{lllll}
\hline \multicolumn{5}{c}{ Mean \pm SD } \\
\hline Resin & 24 hours & 72 hours & Group total & $p$ value \\
\hline SDR & $0.60 \pm 0.89$ & $0.20 \pm 0.45(\mathrm{~A})$ & $0.40 \pm 0.70(\mathrm{a})$ & $p(1)=0.722$ \\
TEF & $2.20 \pm 1.10$ & $1.60 \pm 0.89(\mathrm{~B})$ & $1.90 \pm 0.99(\mathrm{~b})$ & $p(1)=0.524$ \\
FBFF & $1.40 \pm 1.134$ & $0.40 \pm 0.55(\mathrm{~A})$ & $0.90 \pm 1.10(\mathrm{a})$ & $p(1)=0.286$ \\
& $p(2)=0.131^{*}$ & $p(2)=0.010^{*}$ & $p(2)=0.005^{*}$ & \\
\hline
\end{tabular}

$\left(^{*}\right)$ significant difference at $5 \%$ (1) By means of the Mann-Whitney test. (2) By means of the Kruskal-Wallis test with paired comparisons of the mentioned test. Note: If all the capital letters in parenthesis differed, this proved significant difference between the resins in the time interval of 72 hours; and if the lower-case letters differed, there were significant diferences between the resins in the total group 
low. This method has been contested because it is an evaluation of a subjective nature, in which the degree of dye penetration is calculated by means of scores. ${ }^{19}$ Therefore, to minimize the inter-examiner subjectivity, in this study, the evaluators underwent a process of calibration and the Kappa index was calculated (K> 82\%). Other techniques have been used to measure the level of microleakage, among them compressed air, electrochemical investigations, scanning electron microscopy, and more recently micro-CT images. ${ }^{20}$ In spite of the advances in technology that allow the use of micro-Ct for the evaluation of microleakage, some authors have reported that the best images were obtained my stereomicroscopy. ${ }^{21}$ According to De Santi et al..$^{22}$ provided that it is good inter- and intraexaminer agreement, any of the techniques can be used. Furthermore, the authors reported that micro-CT is still not ready to substitute the method of scores as the gold standard in the evaluation of microleakage.

The capacity of microorganisms for penetrating along the filling and for attaining the periapical tissues is favored by ineffective cervical sealing, ${ }^{23}$ and by the presence of gaps between the restorative material and dentin wall and/or between the gutta-percha and dentin walls of the root canal. ${ }^{24}$ The presence of these gaps may be attributed the diverse causes, such as internal anatomy of the canal; biomechanical preparation; physicochemical properties of endodontic materials; properties of irrigants and filling techniques. ${ }^{25}$ Nevertheless, various studies ${ }^{3,4,26,27}$ have shown that the materials available for this purpose have not been capable of definitively impeding the penetration of fluids and bacteria, in agreement with the data obtained in the present study. However, the proposal of the materials evaluated in this study was to offer a lower level of polymerization contraction and stress. What the data in the literature does allow us, is to identify which material presents the greatest efficacy relative to cervical sealing, thereby reducing the risk of bacteria penetrating along the canal, and improving the success rates of endodontic treatment.

\section{CONCLUSION}

The bulk-fill flow resins evaluated were incapable of promoting hermetic sealing of fillings in the root canal system. Therefore, the binary variable cervical sealing/ root canal filling needs to be performed in an adequate manner; and further researches are required with the purpose of developing a material that is capable of preventing endodontic failures to the maximum extent.

\section{REFERENCES}

1. Roy D, Chowdhury F, Shaik MM, Alam MK. Apical sealing ability of resilon/epiphany system. Dent Res J.2014;11(2): 222-227
2. Al-Maswary AA, Alhadainy HA, et al. Coronal Microleakage of the Resilon and Gutta-Percha Obturation Materials with Epiphany SE Sealer: An in vitro Study. J Clin Diagn Res.2016;10(5):39-42.

3. Damman D, Grazziotin-Soares R, Farina AP, et al. Coronal microleakage of restorations with or without cervical barrier in root-filled teeth. Rev Odonto Sci 2012;27(3):208-212.

4. Shetty k, Habib VA Shetty SV, et al. An assessment of coronal leakage of permanent filling materials in endodontically treated teeth: An in vitro study. J Pharm Bioallied Sci. 2015;7(Suppl 2):S607-S611.

5. Manne US, Sunil K, Arvind K, et al. Comparing marginal microleakage of three Bulk Fill composites in Class II cavities using confocal microscope: An in vitro study. J Conserv Dent. 2015;18(5):409-413.

6. Adnan S, Khan FR. Comparison of Micro-Leakage Around Temporary Restorative Materials Placed in Complex Endodontic Access Cavities: An In-Vitro Study. J Coll Physicians Surg Pak. 2016;26(3):182-186.

7. Tavangar M, Tayefeh Davalloo R, Darabi F, et al. A Comparative Evaluation of Microleakage of Two Low-Shrinkage Composites with a Conventional Resin Composite: an In Vitro Assessment. J Dent. 2016;17(1):55-61.

8. Ilie N, Bucuta S, Draenert M. Bulk-fill Resin-based Composites: An In Vitro Assessment of Their Mechanical Performance. Oper Dent. 2013;38(6):618-625.

9. Bucuta S, Ilie N. Light transmittance and micro-mechanical properties of bulk fill $v s$. conventional resin based composites. Clin Oral Investig. 2014;18:1991-2000.

10. Yoshida Y, Yoshihara K, Nagaoka N, et al. Self-assembled nano-layering at the adhesive interface. J Dent Res. 2012; 91(4):376-381.

11. Torabinejad M, Ung B, Kettering JD. In vitro bacterial penetration of coronally unsealed endodontically treated teeth. J Endod. 1990;16(12):566-569.

12. Alshali RZ, Silikas N, Satterhwaitey D. Degree of conversion of Bulk Fill compared to convencional resin composites at two time inervals. Dent Mater 2013;29(9):213-217.

13. Garcia D, Yaman P, Dennison J, et al. Polymerization Shrinkage and Depth of Cure of Bulk Fill Flowable Composite Resins. Oper Dent 2014;39(4):441-448.

14. Lopes GC. Novas Tendências: Resina composta de baixa contração. InterJ Braz Dent.2009;5(1):12-16.

15. Khayat A, Lee SJ, Torabinejad M. Human saliva penetration of coronally unsealed obturated root canals. J Endod.1993;19(9):458-461.

16. Chailertvanitkul P, Saunders WP, MacKenzie D, et al. An in vitro study of the coronal leakage of two root canal sealers using an obligate anaerobe microbial marker. Int Endod J.1996;29(4):249-255.

17. Mavec JC, McClanahan SB, Minah GE, et al. Effects of an intracanal glass ionomer barrier on coronal microleakage in teeth with post space. J Endod 2006;32:120-122.

18. Barthel CR, Moshonov J, Shuping G, et al. Bacterial leakage versus dye leakage in obturated root canals. Int Endod J. 1999;32:370-375.

19. Umer F, Naz F, Khan FR. An in vitro evaluation of microleakage in class $\mathrm{V}$ preparations restored with Hybrid versus Silorane composites. J Conserv Dent. 2011;14(2): 103-107.

20. Swain MV, Xue J. State of the art of micro-CT applications in dental research. Int J Oral Sci. 2009 Dec;1(4):177-188. 
21. Chen X, Li P, Wang X, et al. Ex vivo antimicrobial efficacy of strong acid electrolytic water against Enterococcus faecalis biofilm. Int Endod J.2013; 46:938-946.

22. De Santi FAA, Pinelli C, Loffredo LCM. Reliability of marginal microleakage assessment by visual and digital methods. Eur J Dent. 2015;9(1):1-5.

23. Gomes AC, Nejaim Y, Silva AIV, et al. Influence of Endodontic Treatment and Coronal Restoration on Status of Periapical Tissues: A Cone-beam Computed Tomographic Study. J Endod. 2015;41:1614-1618.

24. Alkahtani A, Al-Subait S, Anil S. An in vitro comparative study of the adaptation and sealing ability of two carrier-based root canal obturators. Sci World J. 2013 May;2013:532023.

25. Saleh IM, Ruyter IE, Haapasalo M, et al. Survival of Enterococcus faecalis in infected dentinal tubules after root canal filling with different root canal sealers in vitro. Int Endod J. 2004;37(3):193-198.

26. Beach CW, Calhoun JC, Bramwell JD, et al. Clinical Evaluation of Bacterial Leakage of Endodontic Temporary Filling Mater J Endod 1996; 22(9):459-462.

27. Newcomb BE, Clark SJ, Eleazer PD. Degradation of the sealing properties of a zinc oxide-calcium sulfate-based temporary filling material by entrapped cotton fibers. J Endod. 2001;27(12):789-790. 